\title{
NILAI-NILAI DAN MAKNA SIMBOLIK TRADISI NGANGGUNG
}

\author{
Di Desa Petaling Propinsi Kepulauan Bangka Belitung \\ Muhamad Edy Waluyo \\ Program Doktor Islamic Studies UIN Walisongo Semarang \\ m.edywaluyo@gmail.com
}

\begin{abstract}
The tradition of Nganggung in Petaling Bangka, Province of Bangka Belitung Islands is a tradition that has been rooted in its community. This study reveals about values and symbolic meanings of the Nganggung tradition in the village of Petaling in which in the tradition have these values of 1) spiritual, 2) economical, 3 ) mutual cooperation and togetherness and 4) political. This tradition also has a symbolic meaning, we can see it at Nganggung attributes such as tudung saji that represents the preservation of the indigenous plants of pandanus forest, as well as means of preserving of lofty values of its ancestors; from its shape, tudung saji resembles a parabole that represents the tradition of Nganggung as a shelter for all; red, as a dominant color of tudung saji symbolizes courage and high work ethic; cord symbolizes the fastener with a diversity of community and a sense of belonging; while talam, a round pan, shape symbolizes the dynamic attitude and flexibility of its inhabitants.
\end{abstract}

Key Words: Nganggung, value, symbolic meaning, tradition, Bangka Belitung.

\section{Pendahuluan}

Semua orang sepakat bahwa di setiap daerah memiliki budaya yang khas sekaligus unik, boleh jadi mirip atau benar-benar berbeda dengan daerah lain. Karena sifat warisan dari satu generasi ke generasi berikutnya secara turun menurun, tradisi melekat erat dalam kehidupan masyarakat. Kumpulan tradisi di sebuah wilayah terakumulasi dalam sebuah wadah yang disebut budaya, sebagai keseluruhan sistem gagasan, tindakan dan hasil karya manusia dalam rangka kehidupan masyarakat yang dijadikan milik diri manusia dengan belajar (Koentjaraningrat, 1996: 3).

Demikian pula halnya dengan tradisi Nganggung, sebuah tradisi yang memiliki kemiripan dengan ritual sedekah/kenduren (jawa), namun memiliki sisi-sisi yang unik, mulai dari tempat sajian, cara mengemas, cara menghantar 
dulang, hingga posisi jama'ah tradisi Nganggung dalam menyantap hidangan. Logika dan struktur simbolis dari tradisi Nganggung ini boleh jadi tidak disadari oleh masyarakat setempat, bahkan mereka sama sekali tidak mengetahui makna simbolik di balik tradisi ini.

Berbagai spekulasi tentang masuknya Islam ke daerah ini disebabkan minimnya data historis yang representatif sebagai referensi penulisan sejarah Islam di Bangka Belitung. Walaupun di zaman kerajaan Sriwijaya (abad ke-7 sd 13) dan Majapahit (akhir abad 13 M) Bangka Belitung kurang diperhitungkan dari segi politis karena dianggap sebagai daerah yang minim sumber daya alam. (Suara Merdeka, 2014).

Sebuah tradisi dilakukan di samping menjaga kearifan lokal, juga tidak dapat dilepaskan dengan komunikasi antar individu atau antara tokoh dengan masyarakatnya. Komunikasi dalam pandangan David W. McCurdy (1979) adalah sesuatu yang sangat esensial untuk kehidupan sosial, di mana satu sama lain bertukar informasi tentang kebutuhan-kebutuhan, bahaya dan pekerjaan yang belum tuntas, yang apabila dikerjakan bersama-sama akan lebih efektif. Tanpa adanya kemampuan untuk melakukan koordinasi terhadap kegiatan-kegiatan mereka, anggota grup akan kehilangan pengalaman adaptif dalam kancah kehidupan sosial (McCurdy, 1979: 49).

\section{Deskripsi Wilayah}

Bangka Belitung sebagai bagian dari wilayah Negara Kesatuan Republik Indonesia melepaskan diri dari propinsi Sumatera Selatan semenjak tahun 2000 berdasarkan Undang-Undang Nomor 27 Tahun 2000 Tentang Pembentukan Provinsi Kepulauan Bangka Belitung tanggal 21 November 2000, dan terdiri dari Kabupaten Bangka, Kabupaten Belitung dan Kota Pangkalpinang. Pada tahun 2003, berdasarkan Undang-Undang Nomor 5 Tahun 2003 tanggal 23 Januari 2003 dilakukan pemekaran wilayah dengan penambahan 4 kabupaten yaitu Bangka Barat, Bangka Tengah, Bangka Selatan dan Belitung Timur. Pada saat ini, propinsi Kepulauan Bangka Belitung masih terdiri dari 6 (enam) kabupaten, yaitu: Bangka, Bangka Barat, Bangka Tengah, 
Bangka Selatan, Belitung Timur dan 1 (satu) kota yaitu Pangkalpinang. Menurut sensus 2012 jumlah penduduk propinsi Kepulauan Bangka Belitung adalah 1.298.168. (http://babel.bps.go.id/2014). Sementara desa Petaling dengan luas 48,27 km² berpenduduk 5.799 jiwa. (http://www.bangka.go.id).

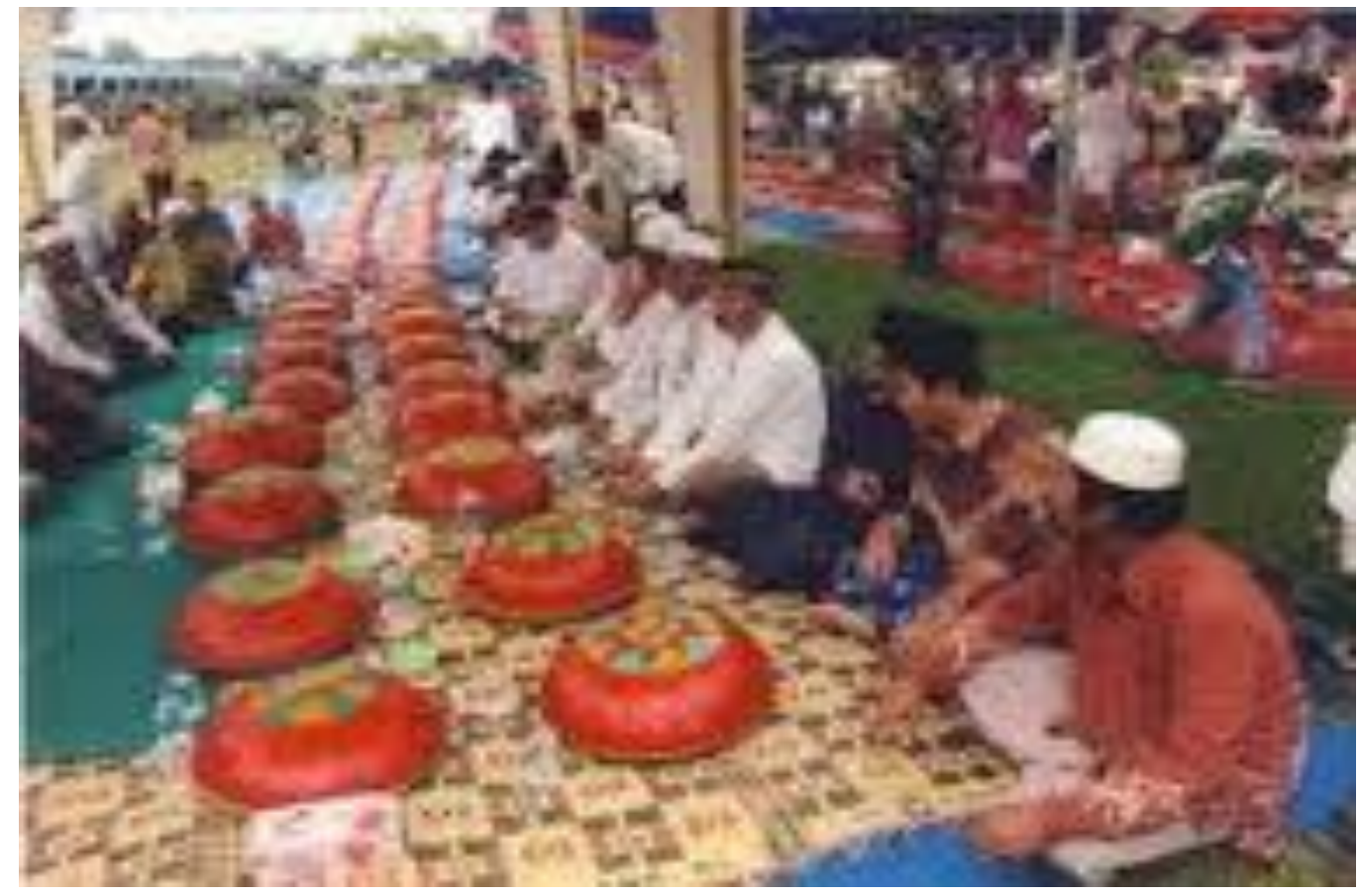

Sumber: Rep. benangkata.blogspot.com

\section{Tradisi Nganggung}

\section{1. Tokoh}

Tokoh dalam ritual Nganggung ini adalah tokoh agama yang sekaligus sebagai tokoh masyarakat desa Petaling maupun Petaling Banjar. Salah satu tokoh Petaling adalah Rudi Karmidi, yang pernah menjabat sebagai kepala desa, sementara di desa Petaling Banjar dipimpin oleh Mahrob yang sekarang masih menjabat sebagai kepala desa Petaling Banjar, sebagai pengurus masjid Jami' al-Istiqomah sekaligus sebagai guru madrasah Tsanawiyah an-Najah Petaling. Tokoh-tokoh lain yang biasanya memimpin 
ritual ini semisal Hidayah (yang disebut warga sebagai guru Dayah), Tengku Bahuri dan guru Ismail.

\section{2. Waktu pelaksanaan}

Ritual Nganggung biasanya dilaksanakan pada hari-hari besar Islam seperti Idul Fitri, Idul Adha, peringatan Nuzul al-Qur'an, peringatan 1 Muharram, peringatan Isra' Mi'raj, peringatan maulud Nabi Muhammad Saw atau juga ruwah kubur, peringatan kematian, melepas jamaah haji dan menyambut tamu-tamu penting. Untuk tradisi Nganggung dua hari raya (Idul Fitri dan Idul Adha) dilaksanakan setelah selesai shalat Id di masjid Jami' dan masjid-masjid kecil. Sementara untuk perayaan maulud Nabi Muhammad Saw dilaksanakan pada malam hari setelah shalat Isya' tanggal 11 Rabi'ul Awwal dan berakhir sekitar pukul 22.00 WIB. Adapun untuk upacara peringatan kematian pada hari pertama dilaksanakan setelah para pelayat kembali dari prosesi penguburan jenazah, sementara hari kedua, ketujuh, keduapuluh lima, keempat puluh, setahun, dua tahun dan seribu harinya dilaksanakan setelah shalat Maghrib atau Isya' tergantung permintaan shahibul hajat. Untuk melepas jama'ah haji biasanya ritual Nganggung dilaksanakan pada jam 09.00 hingga selesai, sementara untuk menyambut tamu-tamu penting waktunya disesuaikan dengan waktu kedatangan tamu.

\section{3. Tradisi Nganggung}

Sebuah bangsa sangat identik dengan kelompok bahasa, sementara bahasa itu identik sekali dengan pemikiran, karena perbedaan itulah yang mendorong setiap masyaraat berfikir secara berbeda. Hal ini menunjukkan bahwa masyarakat tetap menahan sifatnya dari waktu ke waktu. Inilah yang kemudian disebut sebagai sikap primordialisme dalam masyarakat. Demikian pula jika dikaitkan dengan tradisi Nganggung, yang dapat dikategorikan sebagai kegiatan yang tetap, tak berubah karena masyarakat desa Petaling merasa canggung untuk melakukan pergeseran dari tradisi yang telah berlaku secara turun temurun. Misalnya dalam hal membawa hidangan untuk 
Nganggung ini ketika beberapa warga ditanya, tidak ada seorangpun yang menyangkal kebolehan membawanya dengan wadah lain, misalnya rantang. Tetapi pada kenyataannya, hingga saat ini tidak ada satupun warga yang berani menghantarkannya dengan wadah tersebut.

Ciri khas dari tradisi Nganggung ini adalah cara masyarakat mengemas makanan talam/nampan (dalam bahasa lokal disebut dulang). Makanan yang disiapkan biasanya terdiri dari sepiring nasi putih, sepiring lempah ikan (ikan yang dimasak dengan bumbu kuning), sepiring gulai ayam atau udang, cumi, tempe, telur ayam ataupun ikan goreng, sepiring sayur darat (sayur dengan bumbu 3 yaitu terasi, garam dan gula, yang biasanya berisi ketimun dan akar keladi darat), atau jamur pelawan (jamur yang hanya tumbuh di pohon pelawan); jamur kelas satu bagi masyarakat Petaling dengan kisaran harga mencapai Rp. 750.000 per kilo (dalam kondisi kering), serta sepiring buah seperti jeruk, apel, anggur, lengkeng dan semangka atau durian jika sudah tiba musimnya. Setelah itu hidangan ditutup dengan tudung saji yang terbuat dari daun pandan hutan yang memiliki warna dominan merah, sementara di bagian atasnya dihiasi dengan warna hijau dan kuning membentuk bidang segitiga yang tersusun rapih membentuk sebuah lingkaran yang memiliki diameter lebih kurang $40 \mathrm{~cm}$. Agar tidak tertukar dengan dulang dan tudung saji milik orang lain, biasanya orang memberi tanda khusus pada tudung saji, dulang dan piring berupa inisial pemilik.

Sebagaimana diungkapkan di atas, Nganggung bukanlah sebuah tradisi yang berdiri sendiri, namun merupakan sebuah paket dari ritual doa dan diakhiri dengan acara santapan bersama. Sebuah hal yang unik adalah bagaimana masyarakat setempat menghantarkan dulang ke tempat hajatan, dengan mengenakan baju muslim dipadu sarung, sementara songkok khas melayu (terbuat dari anyaman rotan/batang resam, sejenis tumbuhan paku) mendominasi. Dulang dibawa dengan tangan kanan sebagai penyangga, sementara tangan kiri mencengkram bibir dulang dan tudung saji agar tidak jatuh. Melangkah cepat memang menjadi tidak mudah, namun bagi mereka 
yang terbiasa nampaknya mudah saja melakukannya. Ketika memasuki rumah ke tempat hajatan, dulang disusun perbaris 5-10 dulang (tergantung dengan luas ruangan yang digunakan), jika rumah tempat hajatan besar maka posisi dulang bisa diletakkan beberapa banjar, atau diletakkan berbaris di beberapa ruangan tempat hajatan itu diselenggarakan. Sementara itu jamaah Nganggung duduk berhadap-hadapan dengan posisi dulang di tengah-tengah.

Setelah doa selesai dilantunkan, satu persatu tudung saji dibuka dan diletakkan di tempat yang lapang. Jamaah Nganggung saling mempersilahkan untuk menyantap hidangan yang mereka bawa. Jamaah boleh menyantap hidangan yang mereka bawa sendiri atau bertukar dengan hidangan di sebelah kanan maupun kiri tempat duduknya. Satu piring munjung nasi putih biasanya juga diedarkan oleh tuan rumah, yang sengaja disiapkan untuk "tambah" beserta segelas air kemasan yang diedarkan secara beranting. Suasana menjadi tampak semarak ketika mereka saling bertukar lauk dan lempah (sayur), nampak guyup dan rukun. Setelah makan selesai, beberapa orang mengedarkan teh manis dan susu hangat, berjalan di antara jamaah sambil menawarkan, "teh maang (panggilan untuk laki-laki dewasa, semakna dengan paman)?" “susu maang?" Ada saja gurauan yang mereka lontarkan, sehingga suasana rumah menjadi riuh. Saling cerita tentang keluarga, kebun dan pekerjaan terkadang juga berbagi informasi adalah bagian yang tak terpisahkan dari kegiatan ini. Menyimak tradisi Nganggung ini pasti akan berfikir dan merasa bahwa yang sakral dari tradisi ini adalah doa dan dzikirnya saja, sementara setelah itu suasana mencair.

Jika ada makanan yang tersisa, maksudnya yang belum disantap maka beberapa orang mengambil inisatif untuk memindahkan nasi putih beserta lauk pauknya ke dalam baskom shahibul hajat, sehingga dapat dipastikan bahwa talam sudah dalam kondisi kosong ketika dibawa oleh pemiliknya masing-masing. Setelah prosesi makan bersama dianggap selesai, sang pemimpin menutup acara dengan mengucap kata-kata penutup berupa ucapan terima kasih kepada para jamaah yang telah bersedia hadir memenuhi 
hajat tuan rumah, kemudian diakhiri dengan bacaan shalawat Allahumma Shalli 'ala Muhammad ... jamaah serta merta menyambut dengan bacaan shallu 'alaihi ... diikuti dengan jabat tangan seluruh jamaah yang hadir.. Dengan demikian berakhirlah acara Nganggung tersebut.

\section{4. Nilai-nilai Tradisi Nganggung}

\section{4. 1. Nilai Spiritual}

Tidak dapat dipungkiri bahwa tradisi Nganggung di desa Petaling memiliki dimensi nilai spiritual, hal tersebut dapat dilihat dari proses pelaksanaannya, di mana sebelum sajian dinikmati bersama terlebih dahulu diawali dengan hadiah Surat al-Fatihah untuk Nabi Muhammad Saw, sahabat-sahabat, keluarganya, arwah para waliyullah terkhusus Syaikh Abdul Qadir al-Jailani, malaikat muqarrabin, para syuhada dan orang-orang shalih, para syaikh dan ahlil kubur, khususnya kepada arwah keluarga yang mengadakan selamatan kematian (shahibul hajat) kemudian diikuti bacaan surat-surat pilihan dilanjutkan dengan tahlil dan doa. Adapun bacaan-bacaannya kurang lebih sama seperti susunan yang ada di buku-buku Tahlil yang dijual di pasaran. Biasanya pemimpin Tahlil mempersilahkan kepada pemuka agama yang lain untuk memimpin doa setelah Tahlil. Doa itu merupakan rangkaian doa pertama yang dipanjatkan kepada Allah, diakhiri dengan bacaan “al-Fatihah!”Doa yang dipanjatkan relatif panjang, karena tokoh agama dan masyarakat meyakini bahwa doa yang panjang lebih dapat diharapkan untuk diijabah atau dikabulkan Allah. Setelah surah al-Fatihah selesai dibacakan, terkadang pemimpin tahlil memberikan kehormatan kepada sesepuh yang hadir untuk membacakan doa ba'da al-Fatihah, yang seolah menjadi ritual wajib di desa Petaling dalam momen doa bersama di masjid selepas shalat Fardhu atau acara-acara seremonial di tingkat desa maupun kecamatan sekaligus menjadi ciri khas masyarakat kabupaten Bangka, terkhusus lagi pada 
tradisi Nganggung. Masyarakat setempat meyakini bahwa doa ini sebagai penyempurna rangkaian doa yang telah dipanjatkan sebelumnya.

\section{4. 1. Nilai Ekonomis}

Dengan tradisi Nganggung geliat ekonomi di pasar desa Petaling semakin bangkit, bukan hanya itu para pedagang keliling yang menjajakan ikan, sayur dan kue dengan sepeda motor, sepeda dan arko menjadi lebih bergairah menjalankan kegiatan ekonomisnya. Tidak ketinggalan toko buah juga banyak memetik manfaat ekonomis dari tradisi Nganggung ini.

Untuk konsumsi harian saja, misalnya masyarakat desa Petaling adalah konsumen ikan laut yang setia. Nampaknya mereka tidak mempedulikan musim, angin Barat maupun Timur, terang bulan atau tidak yang membawa pada konsekuensi naik turunnya harga ikan, masyarakat desa Petaling tetap mengkonsumsi ikan sebagai lauk. Bahkan sering terdengar celetukan mereka, "kalok dek maken ikan ase-ase dek maken" (jika tidak makan ikan ini seolah-olah belum makan). Sebagai contoh, ikan Tenggiri memiliki rentang harga antara Rp. 35.000 - Rp. 95.000, ikan Kembung dengan rentang harga antara Rp. 35.000 - Rp. 45.000, cumicumi dengan rentang harga Rp. 30.000 - Rp. 60.000,- menjadi alternatif pilihan lauk masyarakat desa Petaling. Belum lagi ditambah untuk kegiatan Nganggung ini, walaupun penambahannya tidak seberapa, bisa diikutkan dalam pembelian untuk konsumsi rumah tangga, tetapi jika diakumulasikan dengan total jamaah Nganggung sekitar tiga puluh sampai empat puluh orang, maka konsumsi ikan tentu akan naik secara signifikan, demikian pula dengan konsumsi buah, sayur dan kue.

\section{4. 2. Nilai Kebersamaan dan Kegotongroyongan}

Nganggung tidak sekedar tradisi makan bersama, namun lebih kental membentuk semangat kebersamaan antara anggota masyarakat. Masyarakat Petaling secara umum, terutama kaum laki-lakinya masingmasing memiliki kesibukan di kebun atau kantor, sehingga momen 
Nganggung menjadi waktu yang sangat tepat untuk bertemu dan bertukar fikiran, sekaligus mencairkan kepenatan dan keletihan bekerja seharian, di mana momen berkumpul seperti ini sering juga diselingi pertanyaan tentang kabar masing-masing dibumbui dengan gurauan-gurauan, sehingga mempererat jejaring sosial antara anggota masyarakat. Jamaah Nganggung tanpa sungkan-sungkan bertukar dulang, menikmati hidangan yang dibawa oleh jamaah yang lain, duduk berhadap-hadapan dengan dulang yang disusun memanjang sehingga memudahkan untuk menyantap hidangannya.

Bila ada tetangga yang terkena musibah kematian, pemuka agama mengumumkannya di masjid Jami' Istiqomah Petaling, dan hal itu biasanya diumumkan beberapa menit sebelum khatib naik mimbar Jum'at bersamaan dengan pengumuman-pengumuman lain. Pengumuman itu dapat berisi himbauan dari Pemerintah Kabupaten berkaitan dengan kependudukan dan ketertiban desa, kegiatan gotong royong membersihkan badan jalan dan selokan, mengingatkan pembayaran $\mathrm{PBB}$, tata cara pengurusan surat-surat ke pemerintah desa sekaligus menghimbau masyarakat yang memiliki keringanan dan kelapangan untuk bersedekah dengan Nganggung kepada keluarga yang berduka. Tanpa harus ditunjuk, masyarakat yang berada di sekitar rumah duka akan segera mempersiapkan hidangan yang akan mereka bawa. Ini menunjukkan semangat kebersamaan dan kegotongroyongan masyarakat yang masih kental.

\section{4. 3. Nilai Politis}

Momen Nganggung kerap kali digunakan sebagai media dari aparat desa maupun kecamatan untuk menyampaikan pengarahanpengarahan berkaitan dengan keamanan, kebersihan, kependudukan dan kegiatan sosial keagamaan. Peristiwa Nganggung seperti ini biasanya bertempat di masjid Jami’ Istiqomah desa Petaling. 


\section{Makna Simbolik}

Manusia tidak dapat melepaskan diri dari simbol. Dalam konteks masyarakat, sebuah simbol dapat saja "sederhana" namun tetap memiliki makna yang merepresentasikan sebuah fenomena. Sejalan dengan hal ini David Jack Eller (2007) mengungkapkan sebagai berikut.

Symbols, in the very simplest construction, are things-objects, images, sounds, actions, gestures, utterances, and almost any other medium - that "mean" something, that "have a meaning." The "meaning" is that which the symbol "stands for," the phenomenon of which it is a representation or a place-holder. Moreover, the relationship between the symbol and its meaning is arguably arbitrary and conventional-that is, there is no necessary connection between the particular meaning and the particular symbol (Eller, 2007: 55).

Berkaitan dengan makna simbolik, sebagaimana yang dimaksud Eller di atas, dalam tradisi Nganggung juga terdapat makna-makna simbolik, khususnya bila dilihat dari dimensi bentuk dari tudung saji, yang menjadi ciri khasnya.

Bahan dasar pembuatan tudung saji adalah daun pandan hutan, sebuah simbol bahwa masyarakat desa Petaling hidup dari kegigihan dan keterampilan mereka mengolah sumber daya hutan yang sebagiannya diolah menjadi perkebunan sawit, karet, lada, palawija dan sayur mayur. Kesadaran tentang asal muasal perjuangan para leluhur yang telah membangun desa sehingga diharapkan generasi-generasi berikutnya memiliki kesadaran dan penghormatan terhadap leluhur yang telah menjaga dan memelihara tanaman langka di tengah maraknya pembukaan kebun secara besar-besaran oleh perusahaan. Penyelenggaraan tradisi ini menuntut masyarakat untuk menjaga hutan-hutan lindung desa sebagai tempat di mana tanaman pandan hutan tumbuh dengan baik, atau memelihara tanaman pandan hutan yang telah dirawat dan dibesarkan oleh pendahulu-pendahulu mereka. Tanaman pandan bagi masyarakat desa Petaling tidak ubahnya sebagai "tanaman adat" yang tetap dimanfaatkan sekaligus dipelihara keberadaannya, sebagai penanda sekaligus wujud dari penghormatan terhadap nilai-nilai luhur para leluhur. 
Bentuk tudung saji seperti parabola, mengandung makna simbolik bahwa keanekaragaman dan perbedaan diakomodasikan dalam satu wadah, sehingga tidak ada warga masyarakat yang lebih istimewa dibandingkan dengan yang lain. Semuanya memiliki hak dan kewajiban yang sama, mendapatkan jaminan keamanan dan kenyamanan untuk tinggal dan beraktifitas di desa Petaling, dari manapun juga asalnya.

Warna merah adalah warna dominan dari tudung saji yang melambangkan keberanian: keberanian untuk berkata benar, sekaligus menggambarkan semangat kerja yang tinggi. Tidak sebagaimana dalam kultur masyarakat Jawa dikenal istilah ewuh pakewuh, dalam pola hidup sehari-hari, masyarakat desa Petaling dengan bahasa yang lugas tanpa tedeng aling-aling mengungkapkan rasa suka atau tidak suka terhadap sesuatu yang mereka hadapi. Ketika misalnya mereka merasa terganggu dengan anggota masyarakat yang melakukan tindakan-tindakan yang meresahkan, mereka tidak segan-segan menegurnya.

Tentang pengikat, antara lembaran-lembaran daun pandan hutan itu diikat dengan tali rotan, demikian pula di bagian bawahnya untuk mengikat jalinan lembaran-lembaran itu digunakan bilah rotan yang dibuat melingkar dua sisi, luar dan dalam, sementara antara rotan dan lembaran-lembaran daun pandan hutan tersebut dirajut dan dikokohkan dengan tali rotan. Sebuah simbol yang menekankan bahwa masyarakat desa Petaling bisa maju dan sejahtera jika perbedaan-perbedaan itu diikat dengan kebersamaan dan sense of belonging (rasa memiliki) terhadap desa di mana mereka bertempat tinggal.

Tentang dulang atau nampan, bentuknya yang bundar, merupakan simbolisasi bahwa masyarakat desa Petaling adalah masyarakat yang dinamis dan lentur.

\section{Simpulan}

Dari paparan di atas dapat disimpulkan sebagai berikut. 
1. Tradisi Nganggung di desa Petaling, Kecamatan Mendo Barat Kabupaten Bangka Propinsi Kepulauan Bangka Belitung memiliki nilai spiritual, ekonomis, kebersamaan dan kegotongroyongan, dan politis.

2. Makna simbolik dari atribut tradisi Nganggung berupa tudung saji adalah: pelestarian tanaman adat berupa pandan hutan, sekaligus bermakna pelestarian nilai-nilai luhur para leluhur; dari bentuknya yang menyerupai parabola melambangkan tradisi Nganggung sebagai pengayom bagi semua; warna merah sebagai warna dominan tudung saji melambangkan keberanian dan etos kerja yang tinggi; tali pengikat melambangkan pengikat keberagaman dengan kebersamaan dan rasa memiliki; bentuk dulang yang bundar melambangkan sikap dinamis dan kelenturan penduduknya.

\section{Daftar Pustaka}

Strauss, Claude Levi. 2005. Antropologi Struktural. Yogyakarta: Kreasi Wacana.

McCurdy, David W. and James P. Spradley. 1979. Issues in Cultural Anthropology, Selected Readings. Canada: Little, Brown \& Company.

Daeng, Hans J. 2000. Manusia, Kebudayaan dan Lingkungan: Tinjauan Antropologis. Yogyakarta: Pustaka Pelajar.

http://babel.bps.go.id/2014, diunduh tanggal 28 Januari 2015.

http://id.wikipedia.org/wiki/Kepulauan_Bangka_Belitung, diunduh tanggal 28 Desember 2014.

http://www.suaramerdeka.com/v1/index.php/ramadan/ramadan_detail/2013/07/10 154479/Lewat-Dagang-dan-Penumpasan-Lanun-Islamisasi-di-Bangka, diunduh tanggal 28 Desember 2014.

Eller, Jack David. 2007. Introducing Anthropology of Religion: Culture to the Ultimate. New York and London: Routledge.

Koentjaraningrat. 1996. Pengantar Ilmu Antropologi. Jakarta: Rineka Cipta.

Masinambow. Editor. 1997. Koentjaraningrat dan Antropologi di Indonesia. Jakarta: Yayasan Obor Indonesia.

Keesing, Roger M. 1981. Antropoogi Budaya: Suatu Perspektif Kontemporer, terj. R. G. Soekadijo. Jakarta: Erlangga. 